Interdisciplinary Studies of Complex Systems

No. 17 (2020) 102-113

(C) S. Ryabchenko

https://doi.org/10.31392/iscs.2020.17.102

\title{
Professional TEACHER'S COMPETENCE IN THE MODERN EDUCATIONAL ENVIRONMENT
}

\author{
Svitlana Ryabchenko ${ }^{1}$
}

\begin{abstract}
This article is devoted to the problem of professional competence formation of future teachers in today's dynamic educational environment that actively develops. In the article the multifaceted definition of "competence" is emphasized, the algorithm of personality formation of competent professionals is outlined, basic types of training are selected, that lay the foundation of professionalism, pedagogical conditions of readiness of teachers to work with gifted students are generalized.
\end{abstract}

Keywords: education, teacher, competence, training, personality and professionalism

At the present stage of development of society and the formation of educational environment there is necessity of qualitatively new teacher training which would allow to combine fundamental professional base knowledge with innovation thinking and practice-oriented researching approach to solving of educational problems. Social and economic changes taking place in the social development of Ukraine make new demands on education to ensure the establishment of a democratic society, and adapting the educational system to the standards of European educational environment.

Professional competence as a quality of a personality has been forming throughout life. Initial professional knowledge, skills, values are founded in school age. Entering a higher education institution, applicants have different levels of knowledge, life experience, values. The task of the university is to prepare highly qualified specialists in the chosen field of profession.

The essence of professional competence is to build on the basis of general education of professionally important for the individual and society qualities that will more fully realize themselves in certain types of work.

The essence of the concept of "competence" integrates a number of definitions of various researchers. For example, N. Bahramova [4] believes that the ability, based on knowledge, education and life experiences, values and aptitudes that can effectively solve problems and tasks arising in real situations of everyday life. According to John Ravenna the competence is a specific capability that is necessary for effective implementation of specific actions in a particular subject area and includes highly specialized knowledge, specific subject skills, and ways of thinking and understanding of responsibility for their actions. [17]. A. Slastenin considers the competence as an integrated de-

\footnotetext{
${ }^{1}$ National University "Chernihiv Kolehium T. H. Shevchenko" svetlanaryabchenko04@gmail.com, https://orcid.org/0000-0001-5376-5443
} 
scription of business and personal qualities of specialist, reflecting not only the knowledge, skills and experience, but social and moral position of the individual [19].

Recently, widespread in terms of scientific debate is the issue of renewal of training future teachers. The school is responsible to society for the quality of graduate education because the level of general education is the basis of common human culture, style of thinking, worldview and spiritual development. In this context, the researchers raise the problem, what is the need-based updates, and take as a basis the contradiction between the increasing demands of society for the individual and the professional competence of teachers and insufficient level of his practical training, personal and technological focus of its activities. Teacher's competence depends largely on practical training. In addition, the teacher's activities in practice should not be directed to a simple transfer of knowledge and the personal development of the child and focus on the needs of the modern school.

Becoming of competent education during the high school training is carried out in accordance with the trajectory of professional and methodological development: information (formation basic knowledge), $\rightarrow$ training (working out of activities ways at practical lessons in methods) $\rightarrow$ practice (pedagogical and educational practice, training course and qualification work) $\rightarrow$ professional self-development based on innovation and information skills. The outlined trajectory points out movement from knowledge to skills and then to scope and competence. Among the knowledge and experience that are formed in achieving individual competence, skills of self-education, critical thinking, self-study, self-organization and self-control, work in a team, the ability to predict the results and consequences of different solutions, find, formulate and solve the problem. Basic knowledge and skills at each level are complemented by meaningful variable component, with each student the individual content of this component.

M. Zyazyun notes that important heritage education of the twentieth century is the triumph of individuality. This means the rise of individual responsibility, that the rise of the cultural level of the individual and the professional [23]. On these grounds the attention is focused on pedagogical knowledge in the training of future teachers.

The essence of the changes taking place today in modern higher education is due to the transfer of science and higher education institutions on the path of market development. High School is to offer the market a model of teacher, it waits, not one that was constantly trained for decades. Therefore, the efforts of lecturers should be directed at upgrading of teacher's training, conversion training on cognitive principle-centered basis, the formation of a competent teacher.

The emphasis should be directed to the substantial components of the training: personal and humanitarian organization; systemic vision of the results of educational activities; psycho-pedagogical diagnosis; formation of reflective and communicative culture; mastering the technique of creative work and innovation; development of organizational capabilities and management of the educational process. In the learning process priority should be independent and individual work of students. [18]. 
There currently is an abundant knowledge-base to inform us that in schools teachers play the critical role in student learning and achievement. Research reveals that how teachers instruct and these interactions with students is the cornerstone around which to build effective schools. A summary of the available studies accumulated over the past 40 years on a key education driver, teacher competencies offers practical strategies, practices, and rules to guide teachers in ways to improve instruction that improves student performance and the quality of the work experience. Four groupings of these competencies can help organize and simply for teachers what they need to master to maximize their performance: classroom management, instructional delivery, formative assessment, and personal competencies. These four categories also provide the essential core around which decision makers can construct teacher preparation, teacher hiring, teacher development, and teacher and school evaluations.

According to the Law of Ukraine "On Education", the Law of Ukraine "On General Secondary Education" the National Doctrine of Education, the State Program "Teacher", the leading position is that the teachers should engage in self-improvement and self-educational activities to improve their level of professional skill. However, the transition to a new educational paradigm should not be limited to a simple increasing in the length of training courses or education. It is essentially about achieving other goals of education, which is to achieve a new level of education of the individual and society as a whole. It should be noted that the new paradigm does not cancel the previous one, it seemed to absorb the usual priorities and declares a higher quality of education.

To base on studying of local researchers, teachers and trainers we outline algorithm of personality formation of competent professionals in the pedagogical university:

- the first step is awareness of career choices, learning pedagogical axioms and acquisition of basic professional skills, consolidating of key competencies that are necessary for further learning and self-improvement;

- the second stage is gaining a wide range of pedagogical knowledge, forming worldview, acquiring professional skills and the basics of pedagogical skills;

- the third stage is the development of analytical skills system, the choice of methodological guidelines, the implementation of pedagogical skills;

- the fourth stage is the development of pedagogical creativity on the basis of self-identity, which is based on acquired knowledge and experience, and professional skills develop to intuitive and empathive level [16].

An important factor throughout each stage is the organization of continuity and relationship between all curriculum disciplines for teacher's training. In addition, the study of each discipline should be focused on the area of maximum personal professional development.

According to the requirements of modern education are distinguished basic types of training that should lay the foundation of professionalism:

- methodological (implementation of general approaches to the process of professional development, development of methods and technologies);

- psychological (the creation of a system to preserve the mental health of the educational process, the development of communication skills, relationships correction); 
- pedagogical (mastering of technology, built on the idea of social responsibility, identifying interests and inclusion in relevant activities);

- didactical (knowledge of the theoretical foundations of modern lessons; the ability to select a set of teaching methods, using of innovative educational technologies, the ability to organize their activities and to adequately evaluate the results of these activities);

- methodical (mastering of content planning, using of ICT, innovative activities);

- managerial (mastering of lessons planning, organizing of own activities and training subjects, monitoring and diagnostics of educational achievements, analysis of results);

- valeological (organization of personal-centered learning based on individual characteristics of students, diagnosis of individual health, implementation of remedial and rehabilitation measures for the preservation and strengthening of health, creating comfortable conditions for the participants of the educational process).

A separate important part of the educational program for professional training of pedagogical universities students is a teaching practice. Organization of students practice at all stages of education should be directed on ensuring of the continuity and succession for mastering the elements of professional activity.

Among the qualitative indicators in the training of future teachers much attention should be paid to the development of this criteria professionalism of the teacher as the abnotivity level, which is a comprehensive ability of the teacher to adequate perception, comprehension and understanding of the creative student or the student's ability to notice a child's talent and ability to provide it with the necessary psychological and pedagogical support [25]. So important pedagogical conditions of teachers training to work with gifted students should be:

- creativity, pedagogical skills of teachers who determine the effectiveness of their interaction with the students in developing their creative abilities;

- personal-centered approach to students training, which involves the formation of the whole person of the future teacher, taking into account the characteristics of individual development;

- availability in the content of educational subjects the material for training of creative teachers (creative tasks, work in the Internet, methods of field studies and experiments in the laboratory, training to take part in various competitions, Olympiads, methods of application of new technologies, etc.);

- didactic support the learning process (author manuals, video lessons, test authoring program);

- creating an atmosphere of partnership between students and teachers, provided by using of interactive learning technologies;

- introduction to the educational process researching problem and searching experimental teaching methods, which involve raising the creative activity of students; 
- using of modern e-learning (electronic textbooks, reference books, encyclopedias, educational software, tests and books of problems) that increase interest in gaining knowledge [13].

Taking into consideration theoretical aspects of the teachers training to work with gifted children methodological principles of training, consisting in directing the educational process of high school the development of creative activity of students and use in the classroom methods of active learning (interactive, information, research) are determined [8].

The teacher always acts in specific situations, so important in the days of training in higher educational establishments to teach students to see the situation, analyze it, provide key ideas underlying the search for its solution, and develop design schemes and options for practical solutions. In such an approach activities such as teaching of pieces lesson, modeling elements of educational projects, solving educational problems, business games, auctions pedagogical ideas and teaching talent contests, contests of improvisation that are part of the total educational technology of formation of professional competence of future teachers are oriented [7].

Research confirms this common perception of a link and reveals that of all factors under the control of a school, teachers are the most powerful influence on student success $[3,15]$. What separates effective teachers from ineffective ones, and how can this information be used to support better teaching? We can now begin to build a profile of exemplary classroom instruction derived from effectiveness research $[21,9]$.

Which competencies make the biggest difference? An examination of the research on education practices that make a difference shows that four classes of competencies yield the greatest results.

1) Instructional delivery

2) Classroom management

3) Formative assessment

4) Personal competencies (soft skills)

Further, the research indicates that these competencies can be used to organize the numerous specific skills and knowledge available for building effective teacher development.

Instructional delivery: Research tells us what can be expected from a teacher employing instructional strategies and practices that are proven to lead to increased mastery of lessons. Better learning happens in a dynamic setting in which teachers offer explicit active instruction than in situations in which teachers do not actively guide instruction and instead turn control over content and pace of instruction to students [9].

Is there a diverse set of practices that teachers can efficiently and effectively use to increase mastery of content for a variety of curricula? The structured and systematic approach of explicit instruction emphasizes mastery of the lesson to ensure that students understand what has been taught, become fluent in new material, and can generalize what they learn to novel situations they encounter in the future.

The following are hallmarks of an explicit approach for teachers $[1,11]$. 


\section{Comparing Instructional Approaches}

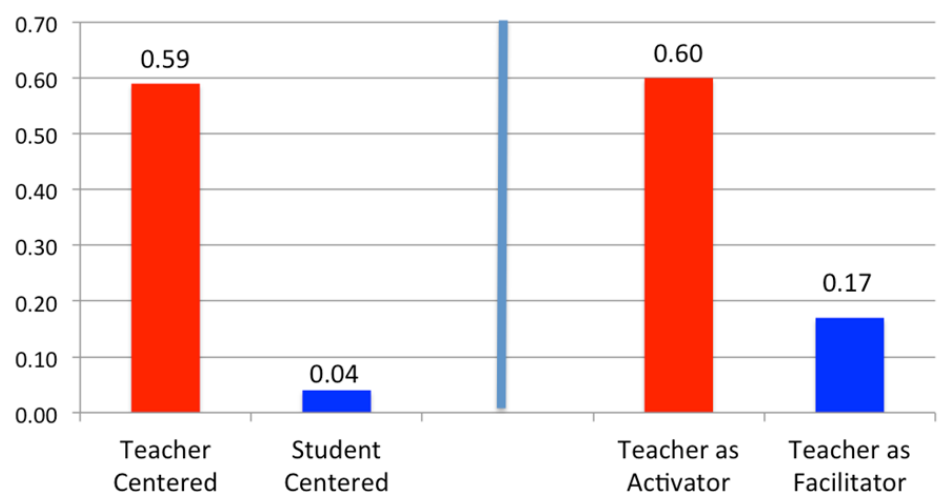

Hattie, 2009

1) Teacher selects the learning area to be taught.

2) Teacher sets criteria for success.

3) Teacher informs students of criteria ahead of the lesson.

4) Teacher demonstrates to the students successful use of the knowledge/skills through modeling.

5) Teacher evaluates student acquisition.

6) Teacher provides remedial opportunities for acquiring the knowledge/ skills, if necessary.

7) Teacher provides closure at the end of the lesson.

A common complaint of an explicit instruction approach is that it does not offer sufficient opportunities for students to build on acquired knowledge/skills in creative and novel ways that help them to assimilate the material. The reality is that all effective instruction, regardless of philosophy, must aid students in generalizing newly taught knowledge/skills in a context that is greater than a single lesson. An explicit model accomplishes the goal of building toward "big ideas" by first emphasizing mastery of foundation skills such as reading and mathematics, and then systematically introducing opportunities to integrate these critical skills in discovery-based lessons to maximize students' experience of success.

Effective explicit instruction practices include these features.

Well-designed and planned instruction: Instruction that is well planned moves students from their current level of competency toward explicit criteria for success.

- Instructional design with clear instructional objectives: The teacher should present these objectives to students for each lesson.

- Scope and sequencing: The teacher should teach the range of related skills and the order in which they should be learned. 
- Instruction that offers sufficient opportunities for successful acquisition:

- High rates of responding for each student to practice the skill: The teacher should provide sufficient opportunities for unpunished errors and ample reinforcement for success.

- Sufficient quantity of instruction: The teacher should allocate enough time to teach a topic.

Teaching to mastery: Students need to learn the knowledge/skills to criteria that are verified by teachers or students' peers. Teaching foundation knowledge/skills that become the basis for teaching big ideas: Current lessons should be built on past knowledge to increase fluency and maintain mastery of material. The teacher should relate lessons to complex issues and big ideas that provide deeper meaning and give students better understanding of the content.

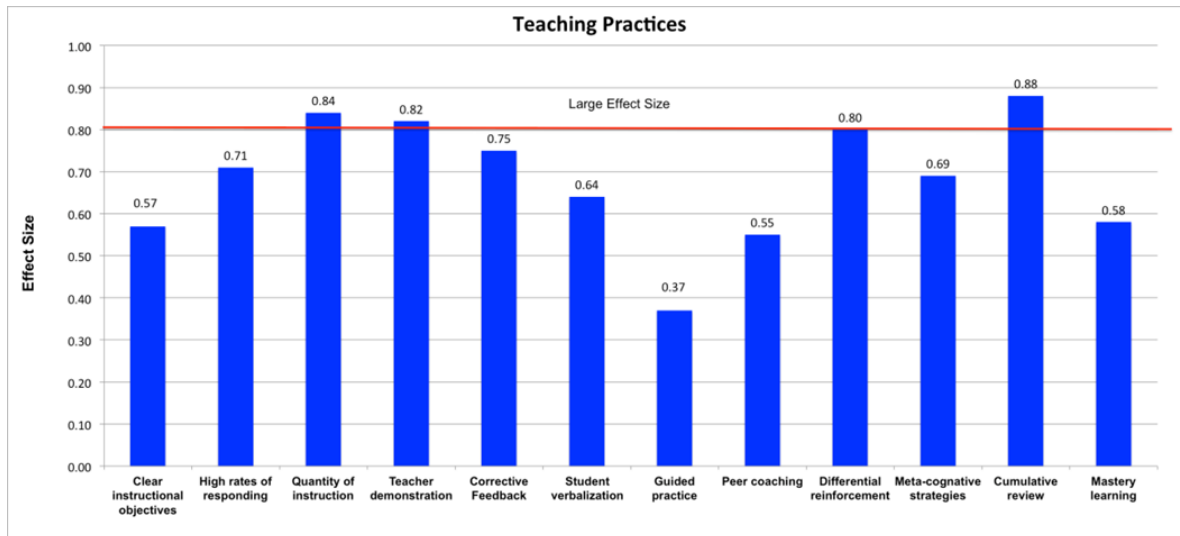

Classroom management: Classroom management is one of the most persistent areas of concern voiced by school administrators, the public, and teachers [24]. Research consistently places classroom management among the top five issues that affect student achievement.

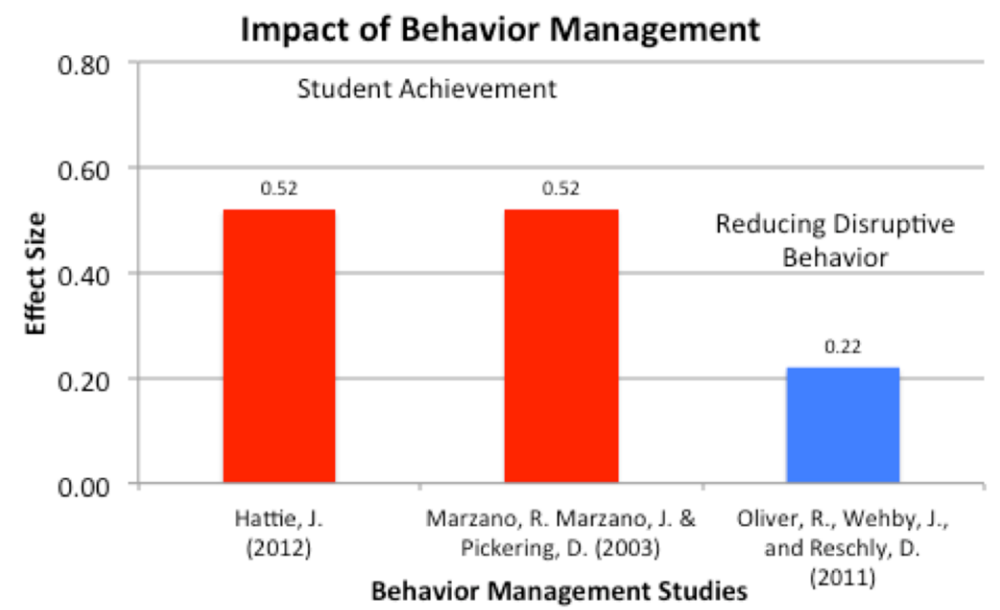


To put its in perspective, classroom management was associated with an increase of $20 \%$ in student achievement when classroom rules and procedures were applied systematically [9].

A good body of research highlights four important areas that classroom teachers should be proficient in to create a climate that maximizes learning and induces a positive mood and tone.

1) Rules and procedures: Effective rules and procedures identify expectations and appropriate behavior for students. To be effective, these practices must be observable and measurable.

- Schoolwide rules and procedures: Clearly stated rules identify, define, and operationalize acceptable behavior specific to a school. These rules, applicable to all students, are designed to build pro-social behavior and reduce problem behavior in a school. They distinguish appropriate from problem behavior as well as specify consequences for infractions.

- Classroom rules and procedures: Another set of clearly stated rules establishes acceptable behavior specific in a classroom. These rules need to be consistent with schoolwide rules, but may be unique to meet the needs of an individual classroom.

2) Proactive classroom management: These are the practices that teachers and administrators can employ to teach and build acceptable behavior that is positive and helpful, promotes social acceptance, and leads to greater success in school. The key to proactive classroom management is active teacher supervision. The practice elements that constitute active supervision require staff to observe and interact with students regularly. The goal is to build a positive teacher-student relationship by providing timely and frequent positive feedback for appropriate behavior, and to swiftly and consistently respond to inappropriate behaviors.

3) Effective classroom instruction: The key to maintaining a desirable classroom climate is to provide students with quality instructional delivery aligned to the skill level of each student. This enables students to experience success and keeps them attentive.

4) Behavior reduction: These practices, designed to reduce problem and unacceptable behavior, are employed in the event the first three strategies fail. Behavior reduction strategies include giving students corrective feedback at the time of an infraction, minimizing reinforcement of a student's unacceptable behavior, and guiding students in how to behave appropriately.

Formative assessment: Effective ongoing assessment, referred to in education literature as formative assessment and progress monitoring, is indispensable in promoting teacher and student success. It is frequently listed at the top of interventions for school improvement [20].

Feedback, a core component of formative assessment, is recognized as an essential tool for improving performance in sports, business, and education. [9] identified feedback as the single most powerful educational tool available for improving student performance, with a medium to large effect size ranging from 0.66 to 0.94 . 
Formative assessment consists of a range of formal and informal diagnostic testing procedures, conducted by teachers throughout the learning process, for modifying teaching and adapting activities to improve student attainment. Systemic interventions such as Response to Intervention (RtI) and Data-Based Decision Making depend heavily on the use of formative assessment $[9,14]$.

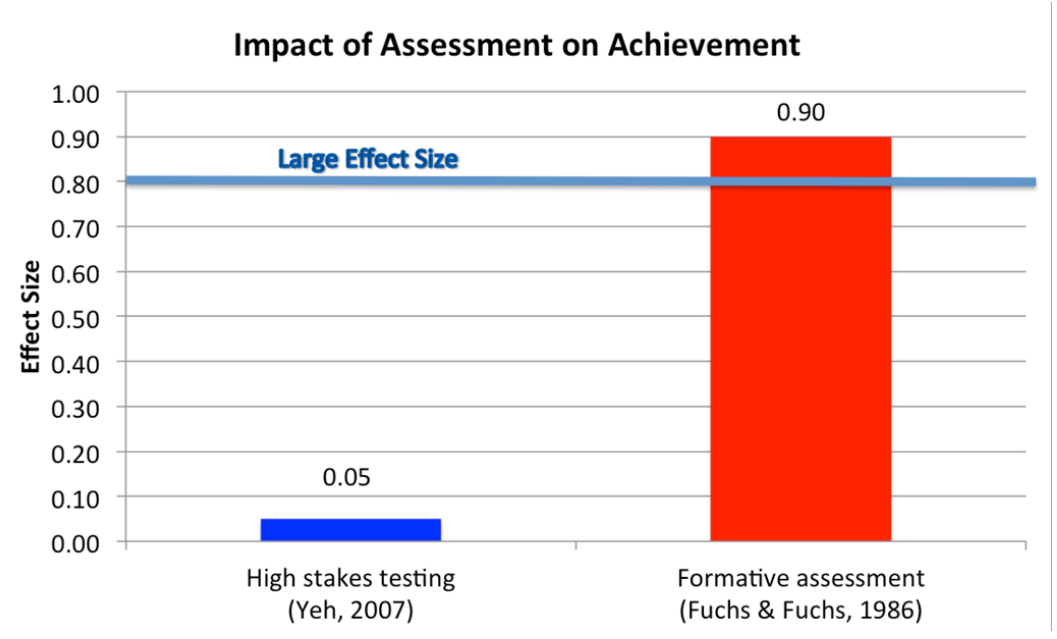

The following are the practice elements of formative assessment [6]. Assessment: (Effect size 0.26) Assessing a student's performance throughout a lesson offers a teacher insight into who is succeeding and who is falling behind. It is important that teachers collect and maintain data gained through both informal and formal assessments.

1) Data display: (Effect size 0.70) Displaying the data in the form of a graphic has a surprisingly powerful effect on formative assessment's usefulness as a tool.

2) Data analysis following defined rules: (Effect size 0.90) Formative assessment is most valuable when teachers use evidence-based research and their own professional judgment to develop specific remedial interventions, before it is too late, for those falling behind.

Personable competencies (soft skills): An inspiring teacher can affect students profoundly by stimulating their interest in learning. It is equally true that most students have encountered teachers who were uninspiring and for whom they performed poorly. Unfortunately, effective and ineffective teachers have no readily discernable personality differences. Some of the very best teachers are affable, but many ineffective instructors can be personable and caring. Conversely, some of the best teachers appear as stern taskmasters, but whose influence is enormous in motivating students to accomplish things they never thought possible.

What soft skills do successful teachers have in common? Typically, the finest teachers display enthusiasm and excitement for the subjects they teach. More than just generating excitement, they provide a road map for students to reach the goals set before them. The best teachers are proficient in the technical competencies of teaching: instructional delivery, formative assessment, and 
classroom management. Equally significant, they are fluent in a multilayered set of social skills that students recognize and respond to, which leads to greater learning [2]. These skills must be defined as clear behaviors that teachers can master for use in classrooms.

Indispensable soft skills include:

1) Establishing high but achievable expectations

2) Encouraging a love for learning

3) Listening to others

4) Being flexible and capable of adjusting to novel situations

5) Showing empathy

6) Being culturally sensitive

7) Embedding and encouraging higher order thinking along with teaching foundation skills

8) Having a positive regard for students

What does research tell us about personal competencies? Quantitative studies provide an overall range of effect sizes from 0.72 to 0.87 for effective teacher-student relations. Better teacher-student relations promote increased student academic performance and improve classroom climate by reducing disruptive student behavior $[22,20]$.

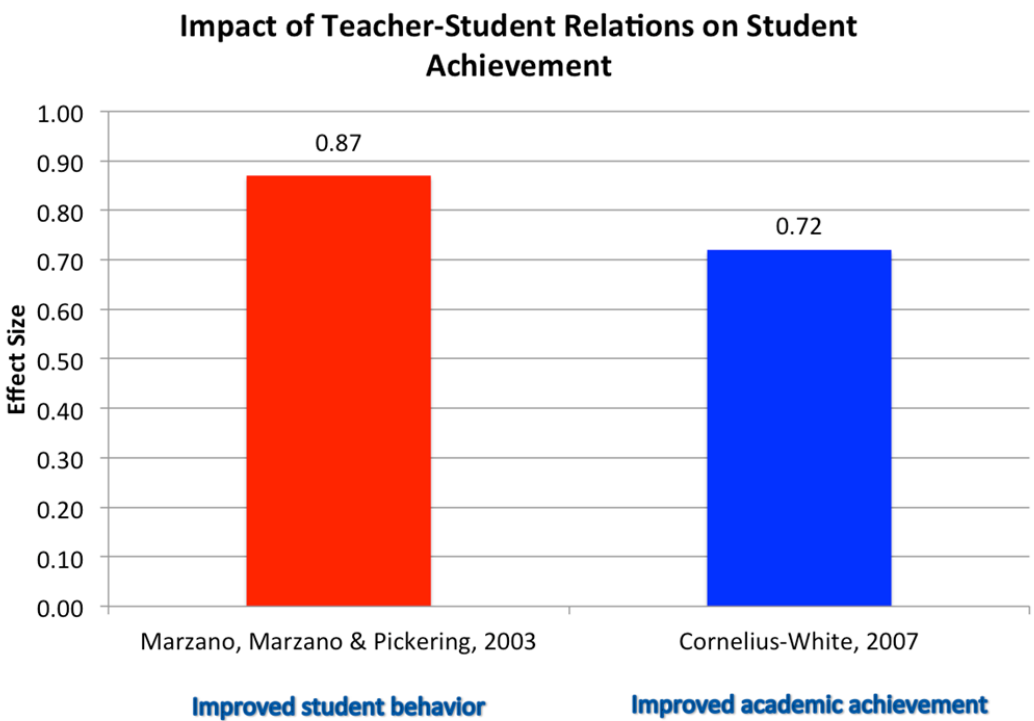

Thus, we can state that the formation of teacher's professional competence in the pedagogical universities becomes more innovative direction. This is shown by researchers focusing on personality-oriented and systematic approach to training (which is the main characteristic features of general competence approach in education), on the basis of scientific, sequence integrity, independence and activity in teaching. It should be noted the presence of researchers' creation for the improvement of organizational and pedagogical conditions of future teachers training, including: using of new forms, meth- 
ods, tools, educational technology, and new semantic filling material. However, many components are considered separately, independently of each other, which can not guarantee efficient as a result of formation of modern teacher's professional competence. So there is a need for a coherent, logical, structural and functional system that would integrate all components into a single process for gaining by students, professional competence of teachers.

\section{References}

[1] Archer, A. L., \& Hughes, C. A. 2011. Explicit instruction: Efficient and effective teaching. New York, NY : Guilford Publications.

[2] Attakorn, K., Tayut, T., Pisitthawat, K., \& Kanokorn, S. 2014. Soft skills of new teachers in the secondary schools of Khon Kaen Secondary Educational Service Area 25, Thailand. Procedia-Social and Behavioral Sciences, 112:1010-1013.

[3] Babu, S., \& Mendro, R. 2003. Teacher accountability: HLM-based teacher effectiveness indices in the investigation of teacher effects on student achievement in a state assessment program. Presented at the annual meeting of the American Educational Research Association (AERA), Chicago, IL, April.

[4] Bahramova, N. V., Kolkova, M. K., Shishkin, J. P. 1999. Using of results for SRW for dimensioned development of professional competence for students of foreign languages faculties in pedagogical high schools. Training of specialists in the sphere of education. SPb, 7:187-197.

[5] Cornelius-White, J. 2007. Learner-centered teacher-student relationships are effective: A meta-analysis. Review of educational research, 77(1):113143.

[6] Fuchs, L. S., \& Fuchs, D. 1986. Effects of systematic formative evaluation: A meta-analysis. Exceptional Children, 53(3):199-208.

[7] Klovak, G. 2003. Content and form of teacher and researcher training in the conditions of pedagogical university, Mother School, 12:46-49.

[8] Knyazeva, O. V. 2009. Using of creative tasks in biology [introduction of personal-centered learning] Biology and Chemistry at school. 1:30-32.

[9] Hattie, J. 2009. Visible learning: A synthesis of over 800 meta-analyses related to achievement. New York, NY: Routledge.

[10] Jackson, P. W. 1990. Life in classrooms. New York, NY: Teachers College Press.

[11] Knight, J. 2012. High-impact instruction: A framework for great teaching. Thousand Oaks, CA: Corwin Press.

[12] Marzano, R. J., Marzano, J. S., \& Pickering, D. 2003. Classroom management that works: Research-based strategies for every teacher. Alexandria, VA: Association for Supervision and Curriculum Development (ASCD).

[13] Mishnyova O. A. 2011. Organization of work with gifted pupils. Biology. 4(February):5-6.

[14] Marzano, R. J., Pickering, D., \& Pollock, J. E. 2001. Classroom instruction that works: Research-based strategies for increasing student achievement. Alexandria, VA: Association for Supervision and Curriculum Development (ASCD). 
[15] Sanders, W.L., \& Rivers, J. C. 1996. Cumulative and residual effects of teachers on future student academic achievement. Knoxville, TN: University of Tennessee Value-Added Research and Assessment Center. Retrieved from http://heartland.org/policy-documents/cumulative-and-residualeffects-teachers-future-student-academic-achievement.

[16] Sysoyeva, S. O. 2005. Modern aspects of teachers training. Pedagogy and Psychology. 4:60-66.

[17] Raven, J. 1981. The Competencies Needed at Work and in Society. Collected Original Resources in Education, 298 p.

[18] Problems of university education in the light of the decisions of the $11^{\text {th }}$ All-Ukrainian Congress of Educators: Proceedings of the All-Ukrainian scientific-practical conference. Part 1. 2002. / Ed. P. V. Dimitrenko and others. Kyiv : NPU after M. P. Dragomanov, 257 p.

[19] Slastenyn, V.A. 2009. Quality of education as social and pedagogical phenomenon Pedagogical Education and Science. 1:4-11.

[20] Walberg, H. 1999. Productive teaching. In H. C. Waxman \& H. J. Walberg (Eds.), New directions for teaching practice and research. Berkeley, CA: McCutchen Publishing. 75-104

[21] Wenglinsky, H. 2002. How schools matter: The link between teacher classroom practices and student academic performance. Education Policy Analysis Archives, 10(12).

[22] White, W.A.T. 1988. A meta-analysis of the effects of direct instruction in special education. Education and Treatment of Children, 11(4):364-374.

[23] Zyazyun, I. A. 2014. The system of consolidated competences and competences in the structure of educational activities and actions of teachers. Pedagogy and Psychology. 3:18-27.

[24] Evertson, C. M., \& Weinstein, C. S. (Eds.). 2013. Handbook of classroom management: Research, practice, and contemporary issues. New York, NY:Routledge.

[25] Pedagogy of Higher School: training appliance 2011. Kyiv : Condor, $628 \mathrm{p}$.

[26] Yeh, S. S. 2007. The cost-effectiveness of five policies for improving student achievement. American Journal of Evaluation, 28(4):416-436. 